\title{
CDISC SDTM Protocol Milestone Terminology
}

National Cancer Institute

\section{Source}

National Cancer Institute. CDISC SDTM Protocol Milestone Terminology. NCI Thesaurus.

Code $C 114118$.

Terminology associated with the protocol milestone codelist of the Clinical Data

Interchange Standards Consortium (CDISC) Study Data Tabulation Model (SDT M). 